\title{
Cópias escolares, anotações de graduandos e resumos criativos do \#Studygram: reflexões sobre a organização da escrita à mão
}

\author{
School copies, undergraduates' notetaking and creative notes \\ of \#Studygram: thoughts on the organization of handwriting
}

Renata Cadena, Wingrid Ribeiro, Melícia França, Solange Coutinho

escrita à mão, anotações, Design da Informação, Studygram handwriting, notetaking, Information Design, Studygram

\begin{abstract}
Este artigo inicialmente apresenta um framework para análise da organização gráfica de textos baseado na observação das formatações aplicadas à linguagem verbal - as chamadas ferramentas textuais gráficas -, assim como o arcabouço teórico utilizado para desenvolvê-lo. O framework é utilizado para entender a configuração da escrita à mão em três contextos: na escrita de crianças e professores do ensino fundamental; em anotações de graduandos em Design Gráfico; e, por fim, nos resumos temáticos e criativos compartilhados na comunidade Studygram, na rede social Instagram. Os resultados apontam que, apesar da formação, estudantes de Design fazem anotações com estrutura semelhante àquela desenvolvida na escola, enquanto os resumos criativos elaborados pelos studygrammers apresentam uma diversidade gráfica maior que a dos dois outros grupos.
\end{abstract}

This paper begins by presenting a framework for the analysis of graphic organization of texts based in the observation of verbal language editions - the so called textual graphic tools -, as with the theoretical basis employed in its development. It is used to understand the configuration of handwriting in three contexts: the writing of teachers and children in elementary school; in notetaking by Graphic Design undergraduate students; and, at last, the colorful notes shared on Instagram by the Studygram community. Results show that, despite their training, Design students notes display similar strategies to the school ones, while notes created by studygrammers have a wider range of solutions than the others.

\section{Introdução}

Apesar da popularização de acesso a recursos digitais que permitem a criação de textos, a escrita à mão perdura nas práticas cotidianas por sua praticidade, rapidez e baixo custo, sobretudo na elaboração de documentos mais informais. É ainda bastante utilizada em contextos educativos e, apesar de ser uma prática cuja aprendizagem se dá 
1 Studygram denomina uma comunidade diversa, de estudantes dos mais diversos níveis, que compartilham rotinas de estudos na rede social Instagram. As postagens variam entre resumos criativos (fichamentos que são formatados com cuidado), dicas de organização pessoal, exemplos de métodos de revisão, entre outros conteúdos (CASTRO; BIADENI, 2019). sobretudo pela repetição de modelos (CADENA, 2018), dispõe de recursos gráficos variados para a organização do conteúdo, mesmo nos primeiros anos do letramento.

Este artigo trata da organização visual da escrita à mão, uma abordagem menos investigada que a configuração anatômica das letras e sua filiação com estilos caligráficos. Pensando neste aspecto, Loaiza, Valencia e Arias (2010) definem a escrita à mão como um tipo de prática caligráfica compromissada com a legibilidade, voltada à comunicação e aprendizagem, e diferente da caligrafia que reproduz modelos históricos ou artística.

Assim, apresentamos os fundamentos da análise, baseada no registro e na classificação das variações gráficas feitas no fluxo do texto - as chamadas ferramentas textuais gráficas (CADENA, 2018). Neste primeiro tópico são discutidas as bases teóricas do framework de análise utilizado: trabalhos advindos dos campos do Design da Informação, da Retórica e da Comunicação Visual.

Em seguida, são apresentadas três pesquisas utilizando esse arcabouço metodológico para analisar documentos coletados em contextos distintos: [1] a investigação de Cadena (2018), que analisou atividades escolares de crianças de 8 anos e de suas professoras; [2] o trabalho de Ribeiro (2020), voltado à comparação da escrita à mão entre designers gráficos em formação em seu primeiro e último período letivo; e [3] a pesquisa de França et al. (2021), voltada, entre outras coisas, à compreensão dos padrões gráficos nos resumos criativos compartilhados na comunidade Studygram. ${ }^{1}$

O interesse da comparação se dá devido à diferença entre os perfis dos criadores e os gêneros envolvidos nas pesquisas. Nas três pesquisas há produções de não-especialistas na criação de linguagem visual, mas no estudo 2 uma parte dos participantes é treinado e tem repertório para a produção de soluções gráficas, nos levando a observar se a configuração da escrita à mão realizada por eles é diferenciada.

Outro interesse está na diferença de gênero textual dos documentos avaliados, pois enquanto nas pesquisas 1 e 2 as anotações feitas por estudantes e docentes são para consumo pessoal, os resumos criativos realizados pelos studygrammers são voltados ao compartilhamento de informações e habilidades técnicas. Assim, mesmo que todos estejam na esfera das anotações para fins educativos, será possível perceber diferenças na prática gráfica.

\section{Fundamentos da análise}

Ainda que a escrita à mão seja uma forma de registro de textos cotidiana e informal, frequentemente para consumo próprio, nela também se percebem recursos diversos de design da informação. Essas diferenciações visuais no texto que são mudanças no fluxo corrido, - as "ferramentas textuais gráficas" são a base do framework 
de análise apresentado a seguir, em que elas são identificadas, contabilizadas, classificadas em sua natureza, função e aplicação no corpo do texto (CADENA, 2018).

\subsection{As ferramentas textuais gráficas}

Para se descrever mudanças visuais realizadas em um texto é necessário caracterizar o texto considerado "normal". Segundo Twyman (1979), a configuração mais convencional da linguagem verbal é a que ele chama de "linear interrompida", em que o texto é partido em linhas sequenciadas justamente porque há um limite de tamanho da mídia, em que as palavras ao chegarem no limite da margem são empurradas à linha de baixo. Dessa maneira, interromper o texto antes da margem demonstra um interesse em separar a informação (edição semântica).

Em outro trabalho, Twyman (1986) descreve a evolução do uso das "pistas" visuais como uma maneira de dirigir e facilitar a leitura, criadas em resposta a novas formas de ler. O crescente interesse em melhorar a usabilidade dos textos promoveu inovações tecnológicas e estéticas na estrutura dos textos, como no uso de fontes em negrito para dar ênfase.

A edição visual de textos reforça a diferença de conteúdo das partes que o compõem, como um título, que é diferente do resto do texto não apenas por sua estrutura linguística, mas também por estar geralmente separado do corpo do texto, sublinhado, ou em outra fonte. Esses atributos visuais foram denominados por Gilreath (1993) como pistas textuais gráficas, inspirando a nomenclatura ferramentas textuais gráficas.

O termo ferramentas destaca que não se trata de modificações visuais aleatórias, mas mediadores utilizados na concretização de conceitos, com finalidade. Para Norrish (1987) a formatação evidencia a estrutura que precede o texto: "a forma final do texto é a forma pela qual ele é fisicamente realizado. Deve-se utilizar os recursos gráficos e espaciais de um sistema para que as diferentes unidades se diferenciem umas das outras, enquanto se torna clara a relação entre essas unidades" (NORRISH, 1987, p. 4, tradução nossa).

A outra conotação da palavra ferramenta refere-se à versatilidade enquanto um dispositivo para a construção de diferentes coisas. Assim, a formação de uma caixa de ferramentas torna-se uma metáfora para o letramento gráfico, em que essa coleção se expande junto com o repertório de alguém que está aprendendo a criar novas soluções informacionais. 


\subsection{O framework}

O estudo das ferramentas usadas na organização visual de textos manuscritos inspirou quatro perguntas:

1. Que ferramenta é essa? Descreve e computa a frequência das ferramentas. Assim, um documento que dispõe de mais variedade de ferramentas pode ser considerado como mais graficamente complexo.

2. Ela é de que tipo? Observa que recurso foi modificado no fluxo do texto para se indicar uma informação diferente, se espaço, texto ou pela adição de outros elementos. Serve à compreensão de que tipo de aspecto a organização do texto escrito à mão mais se baseia.

3. Para que é usada? Indica o papel que a ferramenta tem na estrutura informacional do texto. O estudo da função é útil para a comparação de textos transcritos, em que frequentemente há uma substituição de ferramentas. Também serve para entender que funções adquire um certo recurso gráfico ou o contrário, quais recursos gráficos são convencionados para determinado propósito.

4. Onde é usada no texto? Aponta em que "nível" do texto a ferramenta foi utilizada. Como a edição do texto acontece em vários níveis, mais pronunciadamente ou minuciosamente, essa análise evidencia as estratégias informacionais convencionadas em diferentes tipos de texto.

Essa abordagem tem uma natureza qualitativa por seus propósitos descritivos e interpretativos, contudo, realizou-se a quantificação de ferramentas textuais gráficas para complementar a avaliação com um ponto de vista mais objetivo. E, apesar de o framework ter sido elaborado para análise da escrita à mão, ele é também compatível com a análise de textos mecanicamente produzidos.

\subsubsection{Que ferramenta é essa?}

Estudando a escrita de cartas e as prescrições advindas de manuais de estilo, Walker (2001) desenvolveu um método usando checklists de atributos visuais comumente usados na escrita desse gênero, identificando assim um espectro de atributos e a frequência com que eram utilizados. Sua pesquisa se diferencia da maioria dos estudos sobre escrita à mão, que tendem a se concentrar na forma das letras, e de estudos sobre organização visual, que focam materiais impressos, feitos por meios mecânicos. Seu método inspirou o procedimento adotado por Cadena (2018), em que são listadas as variações visuais usadas de acordo com demandas informacionais da estrutura do texto, monitorando também a frequência. 


\subsubsection{Essa ferramenta é de que tipo?}

Twyman (1979) exprime as possíveis expressões que a linguagem gráfica pode adquirir nos modos de simbolização verbal-numérico, pictórico e esquemático, no entanto, é difícil destrinchá-los na análise documentos multimodais, em que esses modos frequentemente se combinam.

Kostelnick (1988), investigando os elementos que codificam a linguagem visual em textos, incluiu o modo espacial junto das categorias alfanumérico/simbólico e gráfico. Essas divisões são similares às pistas visuais elencadas por Gilreath (1993): as tipográficas, espaciais e de marcação (elementos gráficos). As ideias desses dois autores foram fundidas nas seguintes categorias:

- Alfanuméricas - Compreende o uso de glifos alfanuméricos como letras, números, símbolos legais e comerciais, pontuação e elementos matemáticos. Modificações nesses símbolos, como mudança de tamanho, cor e forma foram também descritas como ferramentas alfanuméricas.

- Picto-esquemáticas - Inclui formas, linhas e ícones, mas não considera, diferentemente de Gilreath (1993), classifica marcadores realizados por letras e números como alfanuméricos.

- Espaciais - Envolve manipulações diversas do espaço relacionado ao texto para além dos habituais espaço entre as palavras e a quebra de linha na margem direita que ocorrem no fluxo de um texto em prosa. Envolve manipulações horizontalmente, verticalmente ou mesmo rotacionando elementos, como recuo, espaço vertical extra, entre outros.

\subsubsection{Para que é usada?}

Cada ferramenta usada é uma resposta a uma necessidade estética ou informacional e, por seu uso versátil, a correlação entre ferramentas e suas respectivas funções não está fechada, variando de acordo com práticas e tecnologias diversas. Em virtude dessa diversidade, a maioria dos livros de consulta sobre tipografia não abordam essa relação. Entre os autores que tratam do tema, Moline (1995) mostra funções como as de organizar e conectar informações; enquanto Rivlin (1987) aponta três funções organizacionais da tipografia: associação, sucessão e atenção; que são relativamente similares às descritas por Mijksenaar (1997): distintivas, hierárquicas e de suporte (voltadas à organização e destaque da informação).

Kostelnick e Hassett (2003) constituíram uma referência chave a partir das funções que definiram para as convenções textuais: estrutura, ênfase, confiança e tom, adaptadas na seguinte proposta de que funções as ferramentas podem indicar: 
- Pertencimento - Definem a estrutura do documento ao delimitar visualmente as suas partes e, por, ao separarem, criarem pequenos agrupamentos de texto, optou-se por usar a expressão indicação de pertencimento" e não ferramentas de agrupamento ou de distinção. Por exemplo, numerar elementos de uma lista serve tanto para agrupá-los, por serem considerados equivalentes, como para diferenciá-los entre si.

- Importância - Apontam ideias principais de um documento, indicando a sequência de leitura ou criando interesse.

- Significado - Criam notações e codificam conteúdos, tanto as mais reconhecidas, como a notação para datas com o uso de barras, como também os códigos particulares usados por grupos específicos, como no uso da letra " $\mathrm{X}$ " por docentes no fundamental para indicar a necessidade de "pular a linha" na cópia.

- Tom - Essa categoria agrupa as ferramentas que trazem uma atmosfera para a informação, abordando o tema indiretamente, de forma que nem sempre têm uma conexão direta com o conteúdo do texto, mas que afetam o seu consumo. Assim, estão compreendidas neste grupo ferramentas inseridas por fins estéticos ou mesmo aquelas cujo propósito informacional não está claro.

\subsubsection{Onde é usada no texto?}

As ferramentas podem ser introduzidas em diversas dimensões da organização de um texto e pensando nessas possibilidades, Twyman (1982) distinguiu as variações na tipografia entre intrínsecas - variações de caracteres (itálico, negrito) - e extrínsecas - modificações nas letras, incluindo mudanças no espaçamento e adição de cor. Já Stöckl (2005), estudando o aspecto semântico da tipografia, segmentou as possibilidades de sua manipulação em quatro domínios: Microtipografia (edição dos glifos), Mesotipografia (modificação nos blocos de texto), Macrotipografia (modificações no documento como um todo) e Paratipografia (materiais e técnicas da produção gráfica). Farias (2016), por sua vez, propondo um modelo para a análise da letra impressa, abrange os níveis: Microscópico (para letras ou parte das letras), Macroscópico (compreende palavras, parágrafos, colunas, páginas e ), e o nível intermediário ou Mesoscópico (que, a depender dos objetivos da análise, pode englobar palavras, parágrafos, colunas e páginas).

Moys (2012) criou categorias com nomes mais populares, inspirados nos softwares de editoração, distinguindo os seguintes atributos: caractere (escolha da fonte e estilo), parágrafo (formatação dos parágrafos), display (arranjo do texto na página), fisicalidade (materialidade), anatômicos (constituição das formas das letras) e de objeto (apresentação de recursos não-verbais). E Kostelnick (1988) propôs quatro níveis em que os elementos que codificam a 
linguagem escrita podem operar: intra-textual (nível de letra e da palavra), inter-textual (estrutura do texto e elementos de layout), extra-textual (elementos pictóricos e diagramas harmonizados com o texto) e supra-textual (consistência no documento). Destacamos também a valorização do layout feita por Waller (2017) como uma qualidade não-linear e ampla do texto: uma infraestrutura para leitura e escrita.

Esses modelos definem a influência nos diferentes níveis a partir do tipo de ferramenta utilizada, mas a abordagem de Cadena (2018) foi inspirada no trabalho de Norrish (1987), cujo método de análise envolvia conhecer a estrutura do conteúdo para depois estudar a sua manifestação gráfica. Assim, as ferramentas não têm atuação fixa num determinado nível, que foram listados dessa forma:

- Documento - Ferramentas que afetam a organização e a navegação do texto por inteiro, como o uso de colunas para aproveitar melhor o espaço.

- Grupos - Ferramentas aplicadas para a diferenciação de partes em que se subdivide o texto, afinal, mesmo a prosa mais contínua traz elementos diversos como títulos de capítulos, notas de rodapé etc.

- Subgrupos - Envolve subdivisões das partes do documento, como por exemplo as frases que compõem o corpo de texto de um manifesto. Logo, para se distinguir subgrupos de grupos, é importante ter em mente o gênero e a estrutura do texto a partir da análise de suas partes.

- Palavra - Envolve ferramentas que não afetam a estrutura do texto, mas que são usadas como pistas visuais ou para propósitos estéticos. Como no uso de itálico para indicar termos estrangeiros, uma edição que não divide o texto, mas que ressalta conceitos a serem notados.

\section{Metodologia de coleta e de análise}

2 O detalhamento do framework pode ser visto em Cadena (2018) e mais dados sobre a pesquisa em Cadena e Coutinho (2019).
É importante contextualizar as três pesquisas apresentadas neste artigo. O estudo 1 teve natureza etnográfica, em que oito turmas do terceiro ano do ensino fundamental (com estudantes de, em média, oito anos de idade) de seis escolas recifenses foram acompanhadas por dez dias cada. As atividades foram registradas por meio de um diário de campo e de fotos das práticas gráficas, sendo selecionadas para análise atividades copiadas e "livres": lições, exercícios e "agenda" escritos no quadro pelos docentes e as respectivas cópias em agendas e cadernos; e os textos livremente elaborados pelos estudantes. Destaca-se a presença de algum tipo de cabeçalho nos textos que não são geralmente extensos, mas divididos em partes menores. ${ }^{2}$

O estudo 2 foi uma análise documental das anotações espontâneas realizadas por estudantes de Design Gráfico no primeiro e no último 
3 Esta pesquisa, assim como as demais, foi submetida $\mathrm{e}$ aprovada por um Comitê de Ética em Pesquisa: no caso das pesquisas 2 e 3 , pelo do IFPB, e no caso da pesquisa 1, pelo da UFPE. sexto e último período de formação. Ribeiro (2020) teve dificuldade em coletar anotações com os estudantes, pois constatou que poucos tomam notas durante as aulas, contabilizando 12 amostras. Pode-se dizer que essa anotação, feita para o registro de informações discutidas em sala, é ainda mais informal que os documentos do primeiro estudo, que são estruturados e têm sua produção monitorada pelos docentes. No caso das notas feitas pelos graduandos, percebe-se a preferência pelo texto organizado em tópicos.

O estudo 3 (FRANÇA et al., 2021) foi voltado para a descrição dos resumos criativos da disciplina de História. Foram coletadas e analisadas 50 amostras publicadas entre 23 e 25 setembro com a tag \#Studygram no Instagram, ${ }^{3}$ randomicamente selecionadas, sendo observada apenas a qualidade da imagem para que se pudesse observar detalhes. A opção pela disciplina se deu por motivos práticos relacionados a outras etapas da pesquisa, não pertinentes a este artigo. Os resumos criativos são fichamentos sobre conteúdos variados que valorizam a formatação para serem apelativos para quem faz e quem consome, estimulando o estudo pela colaboração e engajamento. Assim, são mais planejados que os documentos dos estudos 1 e 2 e seu uso não é apenas individual. A estrutura mais convencional que adotam também é a distribuição em tópicos.

As pesquisas não adotaram exatamente o mesmo procedimento de análise. No terceiro estudo foi feita uma adaptação do framework, concentrando-se na descrição do conjunto de ferramentas e na observação se havia e quais eram as ferramentas destinadas à função de indicar tom. Além disso, a contabilização da frequência das ferramentas foi diferente, pois nos estudos 1 e 2, elas foram contabilizadas sempre que adotadas como estratégia para organizar um conteúdo no documento, enquanto que, na pesquisa 3, apenas se contabilizou a sua existência ou não naquele documento. Assim, o significado dos números é diferente para cada uma das pesquisas, mas servem à compreensão das ferramentas preferidas.
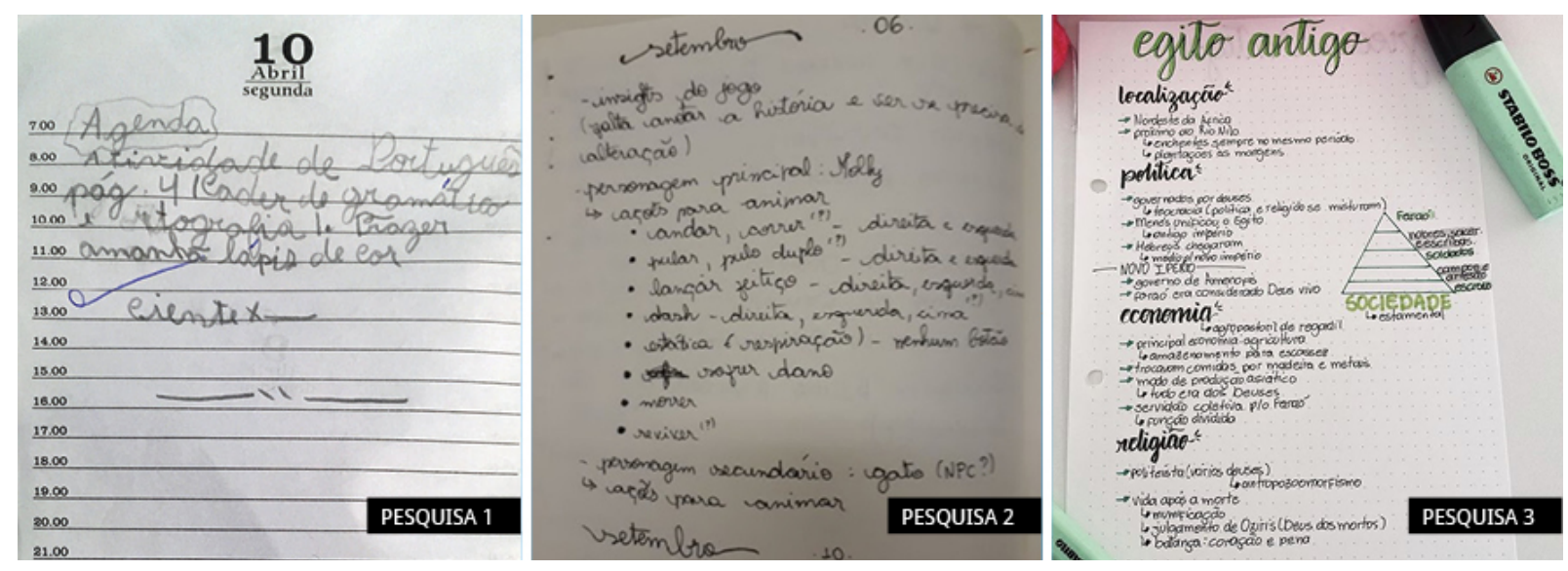

Figura 1 Exemplos de amostras coletadas nas pesquisas. Fonte: as autoras. 


\section{Apresentação e discussão dos resultados}

Neste tópico, a comparação entre os estudos concentra-se nos aspectos comuns da análise desses documentos e é feita no decorrer da apresentação dos resultados, sendo resumida num diagrama final que põe as três caixas de ferramentas em paralelo.

\subsection{Escrita à mão no contexto escolar}

Cadena (2018) analisou cerca de mil amostras de atividades escolares produzidas por professores e suas respectivas cópias realizadas por estudantes, em uma comparação que visava discutir sobre a influência do docente e a formação de referências acerca de estruturas de organização da informação. Em sua pesquisa, ela observou que professores de fato influenciam os discentes e essa perspectiva está incorporada na aprendizagem da organização da escrita à mão. Há uma recorrência de soluções gráficas entre os dois grupos, mesmo quando os estudantes estão livres para organizar a informação. Contudo, existem também preferências pessoais na escrita, pois mesmo quando se espera a cópia da solução informacional, estudantes utilizam ferramentas próprias.

Neste artigo, contudo, nos interessa sua reflexão genérica sobre a organização da escrita à mão, apesar de descrever um contexto educativo do ensino fundamental. Elencamos, aqui, aspectos principais, subsidiados pela Figura 2.

As principais ferramentas são as espaciais, especialmente na manipulação do espaço vertical, mas também do alinhamento

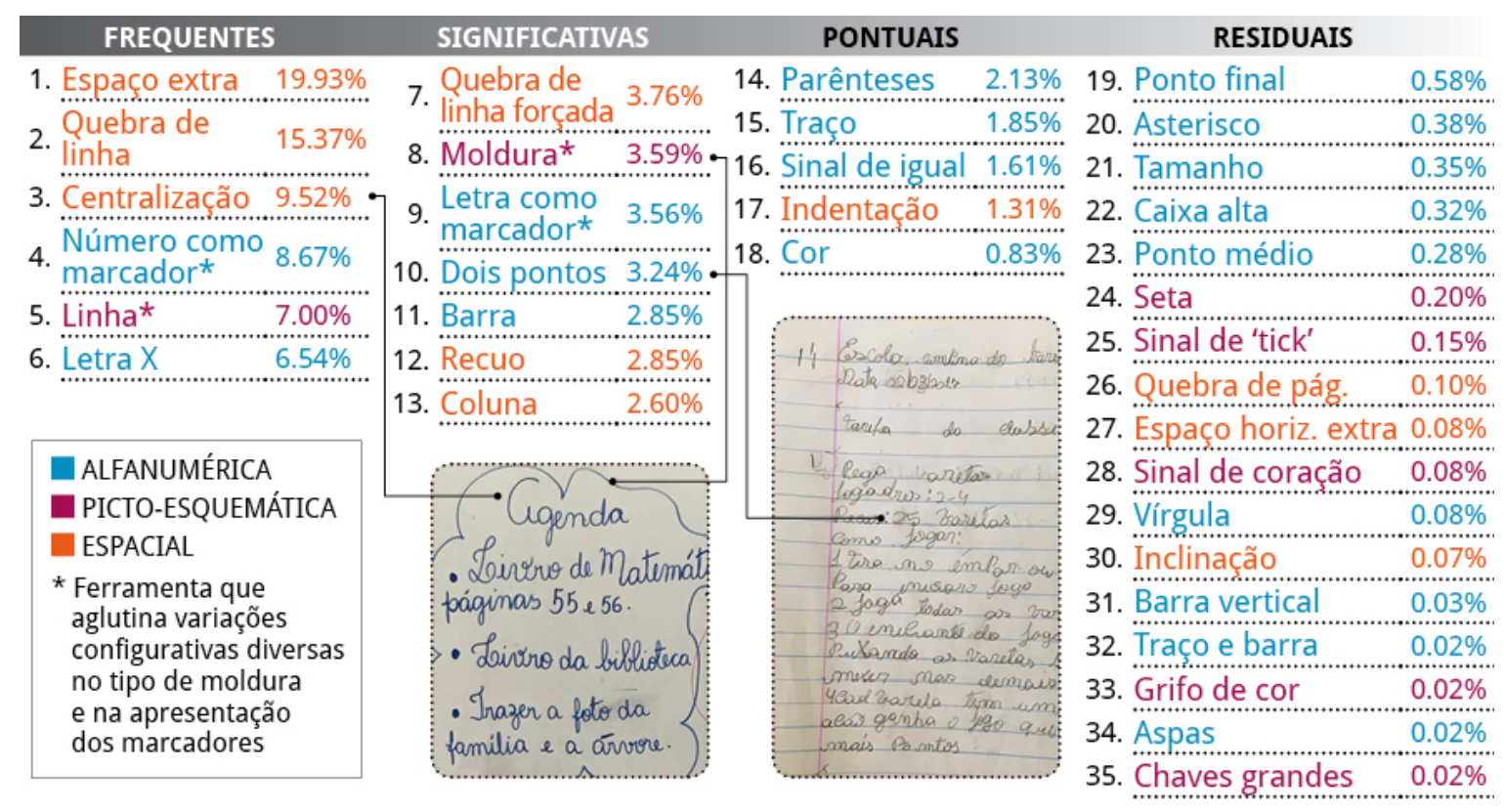

Figura 2 Ferramentas usadas no contexto escolar do ensino fundamental. Fonte: as autoras. 
do texto (centralização). Acerca das ferramentas alfanuméricas, elas são mais glifos do que variações nos mesmos (tamanho, cor, peso), que apesar de serem relativamente fáceis de se produzir à mão, não são convencionais nesse contexto. As ferramentas pictoesquemáticas foram menos exploradas e mais concentradas nas linhas e molduras, que, contudo, foram diversificadas nos estilos (ondulados, arredondados etc.).

A função mais desempenhada foi a de indicar pertencimento e todos os três tipos de ferramentas realizaram essa função. Porém, as alfanuméricas foram as preferidas para casos mais particulares a nível da palavra enquanto ferramentas picto-esquemáticas foram as preferidas para organizar grupos e subgrupos. Houve ferramentas que foram usadas para vários propósitos, como o recuo, que serviu às quatro funções, mas em geral as ferramentas picto-esquemáticas foram as mais versáteis, servindo de sublinhado ou separando blocos de texto.

Acerca do nível em que as ferramentas foram mais utilizadas, observou-se uma maior concentração nos grupos e subgrupos, sendo menor a variedade e a incidência de edições no nível da palavra e, sobretudo, do documento. As produções feitas à mão geralmente são mais informais, exigindo menos planejamento do leiaute e, assim, menos ferramentas aplicadas a nível de documento, assim como há menos facilidades técnicas de variação no estilo da letra.

\subsection{Escrita à mão por especialistas em formação}

Ribeiro (2020) pretendeu observar se a formação em Design Gráfico afetava a maneira como as pessoas tomavam notas, ou seja, se a configuração era mais diversificada ou usava soluções criativas. A comparação entre as anotações de estudantes calouros com as dos veteranos mostrou que não há uma variação significativa nas estratégias de organização da informação: as ferramentas mais usadas, os tipos, as funções e os níveis são semelhantes. Contudo, percebe-se que os alunos veteranos usam mais ferramentas e exploram mais outras funções e níveis: seus projetos são ligeiramente mais diversificados.

Todavia, se nos concentramos no cômputo das amostras analisadas, os principais aspectos são descritos a seguir (Figura 3).

Semelhante à pesquisa 1, as principais ferramentas são as espaciais e de manipulação do espaço verticalmente, mas percebe-se uma maior exploração do espaço horizontal, com o uso frequente de recuo e de colunas. As ferramentas alfanuméricas continuam sendo principalmente glifos, com a edição do texto na variação de alfabeto (caixa alta) e de tamanho. E as ferramentas picto-esquemáticas continuaram sendo as menos usadas, mas dessa vez percebe-se uma proeminência de setas usadas para relacionar conteúdos.

A grande maioria das ferramentas, tanto em diversidade como em recorrência, foi usada para indicar pertencimento, seguida por 


\begin{tabular}{|c|c|c|c|c|c|c|c|}
\hline \multicolumn{2}{|c|}{ FREQUENTES } & \multicolumn{2}{|c|}{ SIGNIFICATIVAS } & \multicolumn{2}{|l|}{ PONTUAIS } & \multicolumn{2}{|l|}{ RESIDUAIS } \\
\hline \multirow{2}{*}{$\begin{array}{l}\text { 1. Quebra de } \\
\text { linha }\end{array}$} & \multirow{2}{*}{$16,9 \%$} & \multirow{2}{*}{$\begin{array}{l}\text { 6. Coluna } \\
\text { 7. Marcador }\end{array}$} & \multirow{2}{*}{$\begin{array}{l}4,9 \% \\
4,9 \%\end{array}$} & \multirow{2}{*}{$\begin{array}{l}\text { 11. Letras maiores } \\
\text { 12. Centralizacão }\end{array}$} & \multirow{2}{*}{$\frac{2,1 \%}{2,1 \%}$} & \multirow{3}{*}{$\begin{array}{l}\text { 21. Chaves } \\
\text { 22. Espaçamento } \\
\text { entre palavras }\end{array}$} & \multirow{3}{*}{$\begin{array}{l}0,7 \% \\
0,7 \%\end{array}$} \\
\hline & & & & & & & \\
\hline 2. Linha extra & $10,6 \%$ & \multirow{3}{*}{$\begin{array}{l}\text { 8. Sublinhado } \\
\text { 9. Vírgula } \\
\text { 10. Recuo extra }\end{array}$} & $4,9 \%$ & \multirow{2}{*}{ 13. Número } & \multirow{2}{*}{$2,1 \%$} & & \\
\hline 3. Seta & $9,9 \%$ & & $3,5 \%$ & & & 23. Linha dupla & $0,7 \%$ \\
\hline 4. Traço & $9,2 \%$ & & $3,5 \%$ & \multirow{2}{*}{ 14. Iniciais } & \multirow{2}{*}{$1,4 \%$} & 24. Polígono & $0,7 \%$ \\
\hline 5. Recuo & $8,5 \%$ & & & & & 25. Grifo de cor & $0,7 \%$ \\
\hline \multirow{2}{*}{\multicolumn{2}{|c|}{$\begin{array}{l}\text { ALFANUMÉRICA } \\
\text { PICTO-ESQUEMÁTICA } \\
\text { ESPACIAL }\end{array}$}} & $\begin{array}{c}20 \\
A_{100}\end{array}$ & & $\begin{array}{l}\text { 15. Asterisco } \\
\text { 16. Caixa alta }\end{array}$ & & 26. Número entre & $0,7 \%$ \\
\hline & & \multirow{4}{*}{ 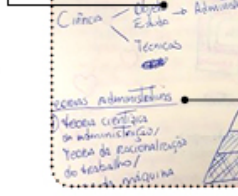 } & & 17. Texto nas & 1,4 & 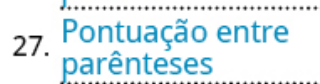 & $0,7 \%$ \\
\hline & & & & 18. Barra inclinada & $1,4 \%$ & 28. Número com traco & $0,7 \%$ \\
\hline & & & & 19. Retângulo & $1,4 \%$ & 29. Parênteses & $0,7 \%$ \\
\hline & & & & 20. Espaçamento & $1,4 \%$ & 30. Linha de divisão & $0,7 \%$ \\
\hline
\end{tabular}

Figura 3 Ferramentas usadas nas anotações de estudantes de Design Gráfico. Fonte: as autoras.

importância, significado e, em quantidade muito menor, tom. As setas foram bastante exploradas nessa função principal, tanto conectando elementos como servindo como marcador.

A distribuição dos níveis foi semelhante à da pesquisa 1, em que subgrupos e grupos foram os níveis em que mais se utilizou ferramentas, e os níveis da palavra e do documento foram menos explorados. Para articular os tópicos do texto (subgrupos), recuos e quebra de linha foram ferramentas bastante exploradas. Ao nível do documento, as colunas foram a ferramenta mais utilizada.

\subsection{Escrita à mão no Studygram}

França et al. (2021) investigaram os resumos da disciplina de História postados na rede social Instagram, que, dada a diversidade gráfica envolvida, foram chamados de resumos criativos. O objetivo da pesquisa foi sobretudo o de caracterizar a estrutura gráfica desse gênero.

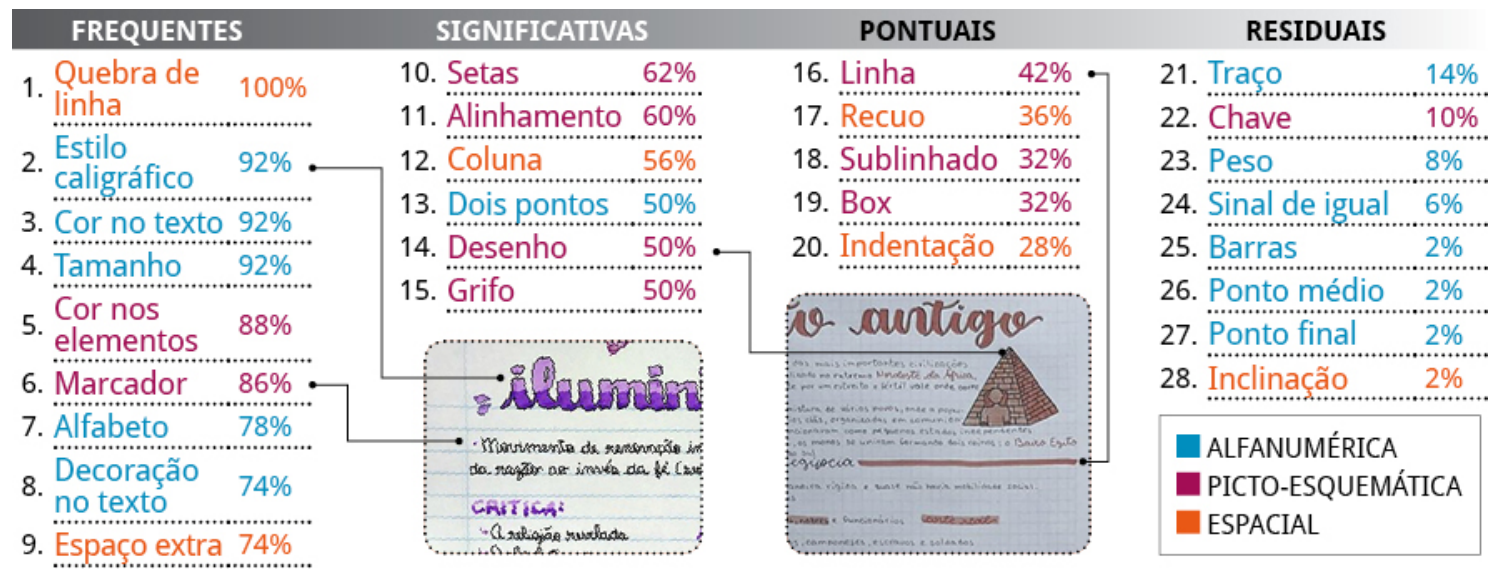

Figura 4 Ferramentas usadas nos resumos criativos. Fonte: as autoras. 
Observou-se o uso de ferramentas alfanuméricas inéditas relacionadas à edição do texto, como a variação do estilo caligráfico (em particular, o chamado brush lettering), decorações diversificadas nas letras (gradiente, sombra, contorno e texturas) e, em menor quantidade, a variação de peso entre letras de mesmo estilo caligráfico. Observou-se que, frequentemente, o corpo do texto estava em letra de imprensa (caixa alta e baixa, geralmente) e os títulos em caixa baixa, sobretudo no estilo brush lettering, mas por vezes apenas no estilo cursivo.

Além disso, houve um uso bem mais frequente de cores, estando presente em todas as amostras - se não no texto, nos elementos pictoesquemáticos. Geralmente se explora apenas uma cor ou esquemas de cores análogas, com poucas composições utilizando cores contrastantes. Quanto à estrutura geral do documento, alguns têm disposição circular e frequentemente a página é dividida em colunas, aproveitando mais o espaço para o texto topificado. Observa-se a presença de tabelas, gráficos e desenhos que explicam conteúdos ou abordam a temática do trabalho.

Nesta pesquisa, não se investigou a função de cada uma das ferramentas. Porém, avaliou-se a presença de ferramentas destinadas à indicação de tom nos resumos, e elas estão em pouco mais de um terço deles. Os desenhos e a decoração das letras (que pode estar sobre ou ao redor delas), seguidos da aplicação de cor em texto ou elementos, foram os principais recursos para conferir uma atmosfera ao documento, trazendo ou não simbologias relacionadas à sua temática.

É possível associar essa variedade de uso de ferramentas inclusive com mais de dois estilos caligráficos e de molduras em um mesmo documento - tanto às convenções desse gênero textual como à maior possibilidade de cuidado com o acabamento, por ele ser realizado com mais tranquilidade e planejamento do que uma anotação ou escrita feita no decorrer de uma aula.

\subsection{Pontuações gerais}

Salvaguardadas diferenças de nomenclatura e de abordagem (exemplo: no estudo 3 não se diferenciou tipos de marcador), o diagrama a seguir mostra convergências na prática da escrita à mão em contextos tão diferentes. Entre as particularidades, percebe-se que alguns elementos são residuais (como o "tick"), outros estão relacionados ao estudo 2 por ter uma amostra tão mais reduzida que os demais. Alguns, contudo, apontam para convenções contextuais: como as edições estilísticas nos resumos criativos; e, na cópia escolar, o uso da letra $\mathrm{X}$, o defeito da quebra de linha forçada e a preferência por marcadores sequenciais (letras e números). 


\begin{tabular}{|c|c|c|c|c|c|c|c|}
\hline \multicolumn{4}{|l|}{ FERRAMENTAS COMUNS } & \multicolumn{4}{|c|}{ FERRAMENTAS PARTICULARES } \\
\hline & ESTUDO 1 & ESTUDO 2 & ESTUDO 3 & & ESTUDO 1 & ESTUDO 2 & ESTUDO 3 \\
\hline Espaço extra & ESP & ESP & ESP & Dois pontos & ALF & & ALF \\
\hline Quebra de linha & ESP & ESP & ESP & Sinal de igual & ALF & & ALF \\
\hline Centralização & ESP & ESP & ESP & Ponto médio & ALF & & ALF \\
\hline Recuo & ESP & ESP & ESP & Ponto final & ALF & & ALF \\
\hline Coluna & ESP & ESP & ESP & Aspas & ALF & & ALF \\
\hline Indentação & ESP & ESP & ESP & Inclinação & ESP & & ESP \\
\hline Espaço horizontal extra/Espaçamento & ESP & ESP & ESP & Vírgula & ALF & ALF & \\
\hline Sublinhado & ESP & ESP & ESP & Marcador & & PIC & PIC \\
\hline Linha & PIC & PIC & PIC & Letra X & ALF & & \\
\hline Moldura/Retângulo/Box & PIC & PIC & PIC & Letra como marcador & ALF & & \\
\hline Seta & PIC & PIC & PIC & Traço e barra & ALF & & \\
\hline Grifo de cor & PIC & PIC & PIC & Barra vertical & ALF & & \\
\hline Chaves grandes & PIC & PIC & PIC & Quebra de linha forçada & ESP & & \\
\hline Número como marcador & ALF & ALF & ALF & Quebra de pág. & ESP & & \\
\hline Barra & ALF & ALF & ALF & Sinal de coração & PIC & & \\
\hline Parênteses & ALF & ALF & ALF & Sinal de "tick" & PIC & & \\
\hline Traço & ALF & ALF & ALF & Estilo caligráfico & & & ALF \\
\hline Cor no texto & ALF & ALF & ALF & Decoração no texto & & & ALF \\
\hline Asterisco & ALF & ALF & ALF & Peso & & & ALF \\
\hline Tamanho & ALF & ALF & ALF & Cor nos elementos & & & PIC \\
\hline Alfabeto (Caixa alta/baixa) & ALF & ALF & ALF & & & & \\
\hline
\end{tabular}

Figura 5 Diagrama comparativo das ferramentas nos três estudos. Fonte: as autoras.

\section{Considerações finais}

Inicialmente, abordamos caminhos teóricos para estudar os propósitos informacionais nas modificações gráficas na linguagem verbal, apresentando um framework dedicado ao estudo das edições executadas no texto, incluindo a análise do tipo, função e níveis de inserção dessas variações. Em seguida, mostrou-se a aplicação do framework em três estudos para a análise de estratégias informacionais na escrita à mão. A partir da comparação da produção de criadores tão distintos, foi possível refletir sobre a organização visual da escrita à mão.

Observou-se que ela é realizada principalmente pela manipulação do espaço - pois a edição de elementos gráficos requer tempo, habilidades, ferramentas. Contudo, quando esses fatores foram favoráveis a uma comunidade motivada, como a do Studygram, de fato, foram incorporados recursos à escrita à mão comuns em textos formatados mecanicamente, como variedade de cor e de estilos caligráficos.

Paralelamente, apesar de terem habilidades, as anotações produzidas por estudantes de Design Gráfico não dispõem de tais ferramentas, adotando soluções próximas às dos documentos realizados no contexto escolar. Contudo, sendo mais experientes na configuração gráfica (junto com os studygrammers), tomam mais liberdades com a disposição dos elementos na página, dividindo-a em colunas, usando recuos e setas para conectar informações sem depender tanto da estrutura linear como no contexto de letramento.

Assim, apesar de seu uso requerer treinamento e atenção, a aplicação do framework em estudos e por pesquisadores diversos mostrou que 
ele possibilita miradas variadas para as soluções informacionais no texto. Investigações futuras envolvem observar práticas de escrita para fins educacionais de outros grupos, visto que as limitações dos estudos apresentados neste artigo estão relacionadas à diversidade de contextos escolhidos: apenas uma série escolar (estudo 1), apenas uma instituição (estudo 2), e apenas uma disciplina (estudo 3). Assim como quanto ao volume das amostras, em especial da segunda (12) e terceira pesquisa (50), quando comparado às mil amostras da primeira.

\section{Referências}

CADENA, R. Sharing textual graphic tools: early lessons in graphic language through practices of handwriting organisation by teachers and pupils in schools in Recife. 2018. Tese (Doutorado em Design) - Centro de Artes e Comunicação, Universidade Federal de Pernambuco, Recife, 2018.

CADENA, R.; COUTINHO, S. G. The visual organization of handwriting: teaching elementary practices of information design in Brazilian primary schools. Information Design Journal, v. 25, n. 2, p. 157-170, 2019.

CASTRO, G.; BIADENI, B. Studygrams: comunicação, consumo e os novos modos de estudar do estudante conectado. CONGRESSO BRASILEIRO DE CIÊNCIAS DA COMUniCAÇÃo, 42., 2019, Belém. Anais [...]. São Paulo: Intercom, 2019. Disponível em: https://portalintercom.org.br/anais/nacional2019/resumos/ R14-1211-3.pdf

FARIAS, P. L. Estudos sobre tipografia: letras, memória gráfica e paisagens tipográficas. 2016. Tese (Livre Docência em Design) - Faculdade de Arquitetura e Urbanismo, Universidade de São Paulo, São Paulo, 2016.

FRANÇA, M.; GUARANÁ, F.; GONÇALVES, G.; CADENA, R. Studygram e design gráfico: contribuições mútuas. Relatório final não publicado (PIBICT). PróReitoria de Pesquisa, Inovação e Pós-Graduação, Instituto Federal da Paraíba, João Pessoa, 2021.

GILREATH, C. Graphic cueing of text: the typographic and diagraphic dimensions. Visible Language, v. 27, n. 3, p. 336-361, 1993. Disponível em: http://eric. ed.gov/?id=EJ 477430

Kostelnick, C. A systematic approach to visual language in business communication. The journal of business communication, v. 23, n. 3, p. 29-48, 1988.

KOSTELNICK, C.; HASSETT, M. Shaping information: the rhetoric of visual conventions. Carbondale: Southern Illinois University Press, 2003.

LOAIZA, F.; VALENCIA, J.; ARIAS, R. Caligrafía expresiva, arte y diseño. Colômbia: Publiprint, 2010.

MIJKSENAAR, P. Visual function: an introduction to information design. New York: Princenton Architectural Press, 1997.

MOLINE, s. I see what you mean: children at work with visual information. Melbourne: Longman, 1995.

MOYs, J. Typographic meaning: readers' impressions of patterns of typographic differentiation. 2012. Tese (Doutorado) - Departamento de Tipografia e Comunicação Gráfica, Universidade de Reading, Reino Unido, 2012. 
NORRISH, P. The graphic translatability of text. Reading: The British Library Board; Department of Typography \& Graphic Communication, 1987. RIBEIRO, W. Escritas à mão em sala de aula: análise das anotações dos alunos de Design Gráfico do IfPв Campus Cabedelo. 2020. Trabalho de conclusão de curso (Tecnologia em Design Gráfico). Coordenação de Design Gráfico, Instituto Federal da Paraíba, Cabedelo, 2020.

RIVLIN, C. A study of the relationship between visual perception and typographic organisation. 1987. Tese (Doutorado) - Institute of Advanced studies, Manchester Polythecnic, Reino Unido, 1987.

sтöскL, H. Typography: body and dress of a text - a signing mode between language and image. Visual Communication, v. 4, n. 2, p. 204-214, 2005. TWYMAN, M. A Schema for the study of graphic language (tutorial paper). In: KOLERS, P. A.; WROLSTAD, M. E.; BOUMA, H. (orgs.). Processing of visible language. Nato Conference Series, v. 13. Boston: Springer, 1979. p. 117-150. TWYMAN, M. Articulating graphic language: a historical perspective. In: WROLSTAD, M.; FISHER, D. (orgs). Towards a new understanding of literacy. New York: Praeger, 1986. p. 188-251.

TWYMAN, M. The graphic presentation of language. Information Design Journal, v. 2, n. 1, p. 2-22, 1982.

WALKER, S. Typography and language in everyday life. London: Longman, 2001. WALLER, R. Graphic literacies for a digital age. In: BLACK, A.; LUNA, P.; LUND, O.; WALKER, s. Information design: research and practice. Abingdon: Routledge, 2017. p. 177-203.

\section{Sobre as autoras}

\section{Renata Cadena}

renata.cadena@ifpb.edu.br

Dra., Professora do IFPB

\section{Wingrid Ribeiro}

wingriddunes@gmail.com

Tecnóloga em Design Gráfico, IFPB

\section{Melícia França}

melicia.yslannye@academico.ifpb.edu.br

Estudante do IFPB

\section{Solange Coutinho}

sol2015ufpe@gmail.com

Dra., Professora da UFPE

Artigo recebido em/Submission date: 5/8/2021

Artigo aprovado em/Approvement date: 2/9/2021 